\title{
Objects and Events: an Investigation into their Identification
}

\section{Riccardo Baratella ${ }^{1}$}

Received: 11 September 2019 / Revised: 11 September 2019 / Accepted: 26 December 2019 / Published online: 21 January 2020

(C) The Author(s) 2020

\begin{abstract}
John goes out for a walk. If John endures and his walk perdures, they are different entities. However, what if both John and his walk perdure? Is John's walk identical to his relevant temporal part? Some philosophers answer in the affirmative. Their motivations rest on ontological parsimony and the quest for clear-cut identity criteria for existing things. By contrast, one of the most widely accepted theories of events - the theory of events as propertyexemplifications - allows us to formulate an argument to the effect that objects' temporal parts are distinct from the events they participate in: the $A I D$ argument, as I shall call it. In this paper, I argue that accepting austere nominalism is the best strategy a supporter of the identification between events and temporal parts of objects can take in order to resist the AID argument.
\end{abstract}

Keywords Events $\cdot$ Objects $\cdot$ Perdurance theory $\cdot$ Universals $\cdot$ Nominalism

\section{Introduction}

My friend John goes out for a walk. Is John identical to the walk? The answer bears on how events and objects persist through time. Events, such as walks, are things that persist by perduring, where "something perdures iff it persists by having different

Riccardo Baratella

baratellariccardo@gmail.com; riccardo.baratella@philosophie.uni-tuebingen.de

1 Department of Philosophy, University of Tübingen, Tübingen, Germany 
temporal parts, or stages, at different times, though no one of it is wholly present at more than one time" (Lewis 1986, p. 202). ${ }^{1}$ Philosophers disagree whether objects, such as John, perdure or endure, where something "endures iff it persists by being wholly present at more than one time" (Lewis 1986, p. 202). If objects endure, then the answer to the identification question is in the negative. However, what if both John and the other objects perdure as events do? Consider John's temporal part that exactly matches his walk's temporal boundaries: is such a temporal part identical to the walk? ${ }^{2}$

Assume perdurance theory for both events and objects. Are then events, such as John's walk, identical to temporal parts of objects, such as John's relevant temporal part? Some philosophers, including Quine (1950, 1960, 1976, 1985), Goodman (1951), and Reichenbach (1956), answer in the positive. ${ }^{3}$ Their motivations rest on the appeal to ontological parsimony ${ }^{4}$ and the quest for clear-cut identity criteria for existing things. ${ }^{5}$ Indeed, the identification allows us to reduce the number of basic kinds of entities (Quine 1976) and it provides events with an allegedly non-problematic criterion of identity - i.e., that for perduring objects (Quine 1985). For instance, Quine claimed that:

Physical objects, conceived thus four-dimensionally in space-time, are not to be distinguished from events or, in the concrete sense of the term, processes. (Quine 1960, p. 171)

If a man whistled a song all the while he was walking to the bus stop and not a moment more, then presumably the event of his whistling the song and the event of his walking to the bus would both be identified with the same temporal segment of the man. (Quine 1976, p. 498).

Despite its theoretical motivations, however, the identification view is incompatible with the intuitive thesis that two or more events can be co-located in the same spacetime region in a way in which objects cannot (Brand (1977), Quinton (1979), Lombard (1998)). For instance, if John catches a cold exactly during his walk, the co-location thesis wants that there are two events in which John participates: John's walk and his catching a cold. ${ }^{6}$ So, John cannot be identical to the events he participates in. As I shall claim, the co-location thesis, and so the rejection of the identification thesis, can be bolstered by one of the most widely-accepted theories of events - the theory of events

\footnotetext{
${ }_{1}^{1}$ Stout (2016) argues that processes, which are a kind of events, endure.

${ }^{2}$ If objects perdure as events do, most reasons to distinguish objects and events are undermined. First, the claim that objects exist, but events occur (Hacker 1982) cannot be explained in terms of the facts that objects endure and events perdure. Second, the claims that objects move and change, but events do not (Hacker 1982; Simons 1987) are based on endurance conceptions of movement and change - conceptions that are not applicable in a perdurance framework. Finally, the claim that objects are centers of stability, but events are not (Strawson 1959) is explained by the view of objects as enduring entities - thesis rejected by assumption.

${ }^{3}$ The view endorsed in (McDonnell 2016, p. 1293) may be considered a recent version of the aforementioned identification view.

${ }^{4}$ Ontological parsimony dictates that we should prefer those theories that postulate fewer basic kinds of entities as long as these are compatible with the phenomena.

${ }^{5}$ An identity criterion is a principle that specifies under what conditions an entity $x$ and an entity $y$ of a kind $K$ are identical.

${ }^{6}$ Brant (1977) and Quinton (1979) support the co-location thesis by modal and causal arguments, respectively. Pianesi and Varzi (2000, section 3) show that these arguments beg the question against the identification view. In any case, I will not attempt to address modal objections against the identification view here.
} 
as property-exemplifications (Goldman 1970; Kim 1976; among others). According to such a theory, events are exemplifications of properties of a certain kind by objects at times. The core principles of this theory allow us to formulate an argument against the identification view: the against identification argument, or the $A I D$ argument for short.

In this paper, I investigate several strategies that the supporter of the identification view (the identifier, for short) may adopt to block the $A I D$ argument. More precisely, I argue that the identifier should resist the AID argument by adopting austere nominalism - the view according to which properties, whether universal or particular, ${ }^{7}$ don't exist. $^{8}$ Furthermore, I also suggest that the identification view and austere nominalism fit so nicely together that they should be considered a unique package - a package that should be evaluated as a whole.

The structure of the paper is as follows. Section 2 characterizes the notion of event and the identification view. Section 3 first presents the theory of events as propertyexemplifications, then assembles the $A I D$ argument. Section 4 divides into three subsections corresponding to three possible options for blocking the $A I D$ argument. In particular, Section 4.3 investigates the nominalist strategies available to the supporters of the Identification Thesis, and it argues that austere nominalism is a perfect partner for the identification view. Finally, Section 5 sums up the main conclusions of this paper.

\section{Basic Notions}

I begin by unpacking the notion of event and what I've been referring to as the identification view. Events are things that happen. In particular, I adopt the standard conception of events, according to which they are spatio-temporal particulars, which can enter into causal relations, which can be observed, ${ }^{9}$ and which can enter into before-after relations (Davidson 1967a, 1967b; Casati and Varzi 2014, among others).

The identification view between temporal parts of objects and events has been introduced by the example of John's relevant temporal part and his walk. A more precise characterization is needed. ${ }^{10}$ For the sake of simplicity, only consider events in which, at first sight, just one temporal part of some object participates. Moreover, for the sake of argument, assume that every temporal part of an object participates in some

\footnotetext{
${ }^{7}$ Particular properties are particulars in the same sense in which individual books and individual trees are particulars. If we admit particular properties, my current temporal part has a mass of $90 \mathrm{~kg}$ because it possesses the property of having a mass of $90 \mathrm{~kg}$. However, such a property is not a universal. It is a particular property of my current temporal part that exists exactly where and when my current temporal part exists (see, e.g., Rodriguez-Pereyra 2015).

${ }^{8}$ According to austere nominalism, the fact that my current temporal part is $90 \mathrm{~kg}$ is metaphysically primitive. So, there is no further metaphysical explanation of this fact that commits to properties of any kind.

${ }^{9}$ I mean "observe" in a quite broad sense: also the measurement of a physical phenomenon counts as an observation of an event.

${ }^{10}$ A concern against this identification may be that some events do not take temporal parts of objects as participants. For instance, suppose being unwilling to count electromagnetic fields as objects, or suppose there are immaterial things, e.g. Cartesian minds. If there can be events taking those entities as participants, then the the category of events referred to in the question whether temporal parts of objects should be identified with events has to be restricted to those events only temporal parts of objects participate in.
} 
event. Then, the thesis that temporal parts of objects are identified with events is specified as follows:

(Identification Thesis) An event $e$ that takes place at a moment $t$ is identical to the object's temporal part participating in it at $t .^{11}$

According to this thesis, every temporal part $x$-at- $t$ of some object $x$ is a part of the entire history of that object, every events $e_{1}$ and $e_{2}$ taking $x$-at- $t$ as the unique participant are identical, and an object just is the mereological sum of the events that happen to it. The Identification Thesis adequately captures Quine's examples. ${ }^{12}$

\section{The Theory of Events as Property-Exemplifications and the AID Argument}

The AID argument is based on the theory of events as property-exemplifications (Goldman 1970; Kim 1973, 1976). According to such a theory, an event $e$ is the exemplification of a property $P$ of a certain kind by some object $x$ at a time $t$. For instance, the state ${ }^{13} s$ denoted by " $x$ 's having a temperature of $30^{\circ} \mathrm{C}$ at $t$ " is identical to the exemplification of the property of having a temperature of $30^{\circ} \mathrm{C}$ by $x$ at $t$. Since I assumed that objects perdure, what is properly meant by "an object $x$ 's having the property $P$ at a time $t$ " is the temporal part $x$-at- $t$ 's having of $P$. So, the event that is $x$-at$t$ 's having of $P$ is identical to the exemplification of a property $P$ by $x$-at- $t$.

I said that an event $e$ is the exemplification of a property $P$ of a certain kind by some object's temporal part $x$-at- $t$. The specification "of a certain kind" is required because, in the present account, not every property $P$ is such that a temporal part $x$-at- $t$ 's having of $P$ gives rise to an event $e$. Let us call the properties that give rise to events "eventive". Generally speaking, sortals - such as being a dog - and properties that don't bestow causal powers - such as belonging to its own singleton - are not eventive. According to Kim, eventive properties "are those properties whose possession by an

\footnotetext{
${ }^{11}$ Concerning events that count just one participant, the identification between an event and its unique participant is clear. If an event $e$ has two or more objects' temporal parts participating in it at a moment $t$, then someone might be willing to identify $e$ with the mereological sum of those temporal parts at $t$. For instance, see Quine (1976). I will leave this complication aside.

${ }^{12}$ A putative reason against (Identification Thesis) concerns the meaning of the notion of participation. According to such an objection, participation is not identity: if $x$ participates in $e$, then $x \neq e$. A plausible reply is the following. On the one hand, the reply points out that the notion of participation cannot presuppose a specific metaphysical view about events and objects on pain of begging the question against the Identification Thesis. On the other hand, it suggests using the notion of participation as a tool that brings attention to bear on the particular entities involved - i.e. $x$ and $e$, without debarring the possibility that $x=e$. Of course, the (Identification Thesis) entails several counterintuitive claims, such as that the walk participates in John. However, the identifiers might reply, such consequences are features of their account and they do not provide knock-down arguments.

${ }^{13}$ I shall use of the notion of state, where this notion has been traditionally understood (Kim (1976), Lombard (1979), Lowe (1998, p. 235)) as follows: "if an object has at some time some static property, $P$, then at that time that object can be said to be in the state of being $P$ " (Lombard 1979, p. 436). Examples of states include $x$-at-t's having a mass of $15 \mathrm{~kg}$ or $x$-at-t's having a temperature of $30{ }^{\circ} \mathrm{C}$. I will side with most of the philosophers involved in the metaphysics of events - among others, Kim (1976), Bennett (1988, § 60), and Varzi (2002) - who consider instantaneous states to be events.
} 
object bestows upon it a causal power or potency, or whose possession by an object indicates its being subjected to such powers" (Kim 1976, p. 37). ${ }^{14}$ Moreover, the theory in question says that eventive properties are universals and events are exemplifications of eventive universals. Hence, I shall speak of eventive universals instead of eventive properties for the sake of clarity.

There are several ways the notion of exemplification has been cashed out. I adopt the view according to which exemplifications of eventive universals - along with those of attributive universals ${ }^{15}$ - are states of affairs (also called "wordly facts"). ${ }^{16}$ According to this framework, a state of affairs is a non-mereological compound whose constituents are - in the simplest cases - a universal $P$ the state of affairs is an exemplification of and a particular that has, or is tied to, the universal $P$. Moreover, states of affairs are particulars in space-time. For instance, suppose it is true that John-at- $t$ has the universal of having a mass of $90 \mathrm{~kg}$. Such a truth is grounded in the state of affairs John-at-t's having a mass of $90 \mathrm{~kg}$, whose constituents are John-at- $t$ and the universal of having a mass of $90 \mathrm{~kg} .{ }^{17}$ Such a state of affairs is a particular in space-time - the space-time region it occupies is that John-at-t is present at. Given that events are exemplifications of eventive universals, it follows that events are states of affairs. Call the thesis that events are states of affairs "Event-Nature". ${ }^{18}$

I shall use the expression " $[x$-at- $t, P]$ " to represent the event identical to the exemplification of the eventive universal $P$ by $x$-at- $t$ - i.e., the event $x$-at- $t$ 's having of $P$. Together with the thesis that events are exemplifications of eventive universals and (Event-Nature), the other two main principles of the theory are (Existence Condition) and (Identity Condition), formulated as follows:

(Existence Condition) Event $[x$-at- $t, P]$ exists if and only if $x$-at- $t$ has the eventive universal $P^{19}$

(Identity Condition) Event $[x$-at- $t, P]=$ event $\left[y\right.$-at- $\left.t^{*}, Q\right]$ if and only if $x$-at- $t=y$-at$t^{*}$, and $P=Q$.

Finally, if there is an event $e$ identical to the exemplification of an eventive universal $P$ by $x$-at- $t$ - i.e. $[x$-at- $t, P]-$, then the event $e$ has $x$-at- $t$ as its participant - call it "Participation" (this principle is used, e.g., in (Kim 1976) and (Bennett 1996)). For

\footnotetext{
${ }^{14}$ See also (Bennett 1988, §36; 1996).

${ }^{15}$ Lowe (2006, p. 14) says that attributive universals are "ways objects are". In other words, attributive universals are those that confer to a temporal part its qualitative character - the qualitative character being that that provides an answer to the question "how is that temporal part like?"

${ }^{16}$ Modulo some difference among its supporters, such a view is associated with the positions developed by, e.g., (Fine 1982), (Moreland 1996, 1998), and (Armstrong 1997).

${ }^{17}$ Some versions of the theory say that the particular involved in the state of affairs is the bare particular associated with John-at- $t$ (see, e.g., Moreland 1996, 1998). In what follows, I leave this complication aside.

18 Another interpretation of the Kimean theory of events says that exemplifications of eventive universals are tropes (such a view is endorsed, for instance, by Bennett $(1988,1996)$ ). According Bennett's notion of trope, tropes are particular tokens of universals - tokens that are borne by temporal parts of objects, and that are present in space-time. Call this version of the theory "theory of events as property-instances". For the purposes of my paper, the two views are equivalent: any argument I shall provide given the theory of events as propertyexemplifications has a counterpart within the theory of events as property-instances.

${ }^{19}$ (Existence Condition) says that the event identical to the exemplification of the eventive universal $P$ by $x$-at$t$ exists if and only if $x$-at- $t$ has $P$.
} 
instance, the exemplification of the eventive universal of having a temperature of $30^{\circ} \mathrm{C}$ by $x$-at- $t$ is an event - i.e., the state $x$-at- $t$ 's having a temperature of $30^{\circ} \mathrm{C}$ - that has $x$-at$t$ as its participant. ${ }^{20}$

We can now state the AID argument. Assume that a temporal part of an object can have two or more distinct eventive universals. Then, consider a temporal part $x$-at- $t$ and two distinct eventive universals $P_{1}$ and $P_{2}$ that $x$-at- $t$ has. There are, by (Existence Condition), the events $e_{1}$ and $e_{2}$ identified with $\left[x\right.$-at- $\left.t, P_{1}\right]$ and $\left[x\right.$-at- $\left.t, P_{2}\right]$ respectively. $e_{1}$ and $e_{2}$ are states of affairs by (EventNature). $P_{1}$ and $P_{2}$ are distinct. Hence, by (Identity Condition), $e_{1}$ and $e_{2}$ are distinct as well. So, we have:

(1) $e_{1} \neq e_{2}$.

Moreover, by (Participation), $e_{1}$ and $e_{2}$ are two states that take $x$-at- $t$ as their participant - i.e., they are two states of $x$-at- $t$.

A plausible instance of the aforesaid situation is this: consider the universal of having a temperature of $30{ }^{\circ} \mathrm{C}$ (in short " $T$ ") and the universal of having a mass of $15 \mathrm{~kg}$ (in short “ $M$ '). These universals are taken to be distinct eventive universals due to the fact that they have distinct causal potencies associated with them. Hence, by (Existence Condition) and (Identity Condition), if a temporal part $x$-at- $t$ has both the universal $T$ and the universal $M$, then there are two distinct states of $x$-at- $t: x$-at- $t$ 's state of having a temperature of $30^{\circ} \mathrm{C}$ (i.e. $[x$-at- $\left.t, T]\right)$ and $x$-at- $t$ 's state of having a mass of $15 \mathrm{~kg}$ (i.e. $[x$-at- $t, M])$. By (Event-Nature), these states are distinct states of affairs of the very same temporal part $x$-at- $t$.

Now, consider the Identification Thesis, according to which an event $e$ that takes place at a moment $t$ is identical to the object's temporal part participating in it at $t$. Given such a thesis, in the case at hand:

(2) $e_{1}=x-a t-t$

(3) $e_{2}=x-a t-t$

(4) $e_{1}=e_{2}$, contra (1)

(2) and (3) are justified as follows: if an event that takes place at a moment $t$ is identical to the object's temporal part participating in it at $t$, then a state that takes place at a moment $t$ of an object's temporal part $x$-at- $t$ is identified with that temporal part. Therefore, by the symmetry and transitivity of identity, we get (4). This shows that the theory of events as property-exemplifications is incompatible with the Identification Thesis. Thus, if one is willing to identify temporal parts of objects and events, one has to reject at least one of the premises of the $A I D$ argument.

\section{Against the AID Argument}

The AID argument depends crucially on three premises. (I) The premise - implied by (Identity Condition) - according to which if there is an event $e_{1}$ identified with $[x$-at- $t$,

\footnotetext{
${ }^{20}$ More precisely, $x$-at- $t$ is the minimal or intended participant of $e$. The characterization of a general notion of participation between events and objects is an open question in the literature on events (for a discussion, see, e.g., Macdonald and Macdonald 2006, footnote 33).
} 
$\left.P_{1}\right]$ and an event $e_{2}$ identified with $\left[x\right.$-at- $\left.t, P_{2}\right]$, and $P_{1} \neq P_{2}$, then $e_{1} \neq e_{2}$. (II) The premise according to which a temporal part of an object can have two or more distinct eventive universals. (III) The premise according to which the thesis that events are exemplifications of eventive universals plus principles (Event-Nature), ${ }^{21}$ (Existence Condition), and (Identity Condition) require some sort of commitment to eventive universals. Each of the premises seems plausible. Still, they entail that a temporal part of an object cannot be identified with an event. In what follows, I examine which of these premises (if any) the identifier should reject to block the AID argument.

\subsection{Many Universals-One Event Solution}

Assume the thesis that events are exemplifications of eventive universals, plus (Event-Nature) and (Existence Condition). Moreover, assume that a temporal part of an object can have two or more distinct eventive universals (premise (II)). Then, the AID argument can be resisted by denying premise (I) - implied by (Identity Condition): if there is an event $e_{1}$ identified with $\left[x\right.$-at- $\left.t, P_{1}\right]$ and an event $e_{2}$ identified with $\left[x\right.$-at- $\left.t, P_{2}\right]$, and $P_{1} \neq P_{2}$, then $e_{1} \neq e_{2}{ }^{22}$ If one is willing to block the $A I D$ argument, one must not only deny such a premise, but one also has to maintain the following stronger thesis:

(Many universals-one event) Necessarily, for any eventive universals $P$ and $P^{*}$, if there is an event $e$ identified with $[x$-at- $t, P]$ and an event $e^{*}$ identified with $[x$-at- $t$, $\left.P^{*}\right], e=e^{*}$.

Such a thesis says that all the events that take $x$-at- $t$ as their participant are identical. But, then, the events $e_{1}\left(\left[x\right.\right.$-at- $\left.\left.t, P_{1}\right]\right)$ and $e_{2}\left(\left[x\right.\right.$-at- $\left.\left.t, P_{2}\right]\right)$ in the $A I D$ argument are identical, contra (1): $e_{1} \neq e_{2}$. Hence, if (Many universals-one event) were plausible, the $A I D$ argument would be blocked.

However, if we conjunct (Many universals-one event) with the accepted principles of the theory of events as property-exemplifications and premise (II), we reach highly implausible results. So, given such assumptions, (Many universals-one event) is implausible, and then the AID argument cannot be blocked by the adoption of such a thesis. The argument is as follows. We assumed that that events are exemplifications of eventive universals. Moreover, given premise (II), suppose that an object's temporal part $x$-at- $t$ has the eventive universals of having a temperature of $30^{\circ} \mathrm{C}$ (in short " $T$ ") and of having a mass of $15 \mathrm{~kg}$ (in short “ $M$ "). By (Existence Condition), there are the following events: $[x$-at- $t, T]$ and $[x$-at- $t, M]$. Within the present framework, $[x$-at- $t, T]$ is identical to the exemplification of having a temperature of $30^{\circ} \mathrm{C}$ by $x$-at- $t$, and $[x$-at- $t, M]$ is identical to the exemplification of having a mass of $15 \mathrm{~kg}$ by $x$-att. By (Many universals-one event):

\footnotetext{
${ }^{21}$ (Event-Nature) says that events are states of affairs. In turn, states of affairs require the existence of universals. So, the acceptance of (Event-Nature) requires the existence of universals.

${ }^{22}$ When the context will be clear enough, I will simply speak of temporal parts instead of temporal parts of objects.
} 
(Many universals-one event) Necessarily, for any eventive universals $P$ and $P^{*}$, if there is an event $e$ identified with $[x$-at- $t, P]$ and an event $e^{*}$ identified with $[x$-at- $t$, $\left.P^{*}\right], e=e^{*}$,

it follows that $[x$-at- $t, T]=[x$-at- $t, M]$, i.e. that the exemplification of having a temperature of $30^{\circ} \mathrm{C}$ by $x$-at- $t$ is identical to the exemplification of having a mass of $15 \mathrm{~kg}$ by $x$-at- $t$.

But, exemplifications of eventive universals are states of affairs. ${ }^{23}$ So, we reach the highly implausible conclusion that a state of affairs whose constituent universal is having a temperature of $30{ }^{\circ} \mathrm{C}$ can be numerically the same as one state of affairs whose constituent universal is having a mass of $15 \mathrm{~kg}$. However, a state of affairs whose constituent universal is having a temperature of $30{ }^{\circ} \mathrm{C}$ is clearly different from a state of affairs whose constituent universal is having a mass of $15 \mathrm{~kg}$, even if such states of affairs are constituted by the same temporal part $x$-at- $t$. Hence, it is plausible to conclude that one cannot resist the $A I D$ argument by saying that events are exemplifications of eventive universals, exemplifications of eventive universals are states of affairs, and by the adoption of (Existence Condition), and (Many Universals-One Event).

\subsection{The Single Eventive Universal Solutions}

The second strategy to resist the AID argument is by denying premise (II): a temporal part of an object can have two or more distinct eventive universals. The adoption of this strategy amounts to maintaining one or the other of the two following theses:

(i) A temporal part can have at most one eventive universal - call it "The Single Eventive Universal Thesis".

(ii) A temporal part cannot have eventive universals at all. This position can be seen as a consequence of the nominalist stance concerning universals - hence, call it "The Nominalist Solution"

In this section, I investigate The Single Eventive Universal Thesis. In the following section, I turn to The Nominalist Solution in association with the rejection of premise (III). I can see only two ways in which The Single Eventive Universal Thesis can be spelled out. I call them the "Complex" and the "Simple" solution, respectively. In what follows, I present these two strategies and argue that they are costly ways of blocking the $A I D$ argument.

\subsubsection{The Complex Solution}

Let me introduce Complex by an example. Consider the situation mentioned in section 3: suppose - for the sake of simplicity - that a temporal part $x$-at- $t$ has just the following universals: the universal of having a temperature of $30^{\circ} \mathrm{C}$ (in short " $T$ "), the universal of having a mass of $15 \mathrm{~kg}$ (in short ' $M$ "), and the universals that can be built out of $T$

\footnotetext{
$\overline{{ }^{23}}$ This follows from the thesis that events are exemplifications of eventive universals and (Event-Nature).
} 
and $M$. According to Complex, the universals $T$ and $M$ are not eventive. Thus, there are no two distinct events $e_{1}$ and $e_{2}$ identified with the exemplification of $T$ by $x$-at- $t$ and the exemplification of $M$ by $x$-at- $t$ respectively. According to Complex, $x$-at- $t$ has exactly one "complex" eventive universal $P$ which is somehow "built out" of $T$ and $M$ (the building relation might be conjunction, but it needs not to be). Therefore, there is just one event $e$ identified with the exemplification of the eventive universal $P$ by $x$-at- $t-$ i.e., $[x$-at- $t, P]$. But, then, the AID argument is blocked. ${ }^{24}$

Complex is a conjunction of three theses. First, The Single Eventive Universal Thesis: every temporal part $x$-at- $t$ of some object $x$ can have at most one eventive universal $P$. Second, such an eventive universal $P$ is a complex (hence the name of the solution) universal built out of other distinct universals $P_{1}, P_{2}, \ldots$ had by $x$-at- $t$. Third, the 'constituent' universals $P_{1}, P_{2}, \ldots-$ which build $P$ - are not eventive. If they were, then premise (II) (the premise that a temporal part of an object can have two or more distinct eventive universals) would be true. So, The Single Eventive Universal Thesis would be false, and the AID argument would hold. ${ }^{25}$

Complex can be called in question. It claims that, in our example, the "constituent" universals $T$ and $M$ of the complex eventive universal $P$ (which is the universal built out of $T$ and $M$ ) are not eventive. However, these constituent universals plausibly qualify as eventive. The argument consists in showing that, for instance, under natural and plausible assumptions, the exemplification of the universal $T$ by the temporal part $x$ at- $t$ satisfies the characterization of the notion of event adopted in this work: events are spatiotemporal particulars which can enter into causal relations, which can be observed, and which can enter into before-after relations. Therefore, it is plausible to conclude that there is an event $e$ identified with exemplification of the universal $T$ by $x$-at- $t$. But, then, $T$ is eventive, contra Complex.

First of all, the exemplification of the universal $T$ by $x$-at- $t$ is a state of affairs - i.e., $x$ at- $t$ 's having of $T$. So, it has the right metaphysical profile to be an event. ${ }^{26}$ Since states of affairs are particulars in space-time (Armstrong 1997), the exemplification of $T$ by $x$ at- $t$ is a particular in space-time. Moreover, the exemplification of the universal $T$ by $x$ at- $t$ can enter into causal relations. It is generally granted that $x$-at- $t$ 's having a temperature of $30{ }^{\circ} \mathrm{C}$ can make a difference concerning the occurrence or the ways of occurrence of some phenomena, i.e. it can enter into causal relations (Menzies 2014). For instance, if $x$-at- $t$ is placed near some snowman, its temperature of $30^{\circ} \mathrm{C}$ concurs to melt the snowman. In the framework adopted, $x$-at- $t$ 's having a temperature of $30^{\circ} \mathrm{C}$ is the exemplification of the universal $T$ by $x$-at- $t .{ }^{27}$ So, the exemplification of $T$ by $x$-at- $t$ can enter into causal relations. By similar considerations, the exemplification of the universal $T$ by $x$-at- $t$ can also be observed. For instance, it can be observed through touch or some measuring instrument. Lastly, the exemplification of the universal $T$ by

\footnotetext{
${ }^{24}$ The solution generalizes for situations in which there are more than two universals involved.

${ }^{25}$ The identifiers may adopt Complex - provided that they assume a view similar to (Armstrong 1997, §8.3): a temporal part of an ordinary object, such as John-at- $t$, is identical to the state of affairs [John-at- $t *, P$ ], where John-at- $t *$ is the thin particular associated with John-at- $t$ and $P$ is the single eventive universal that - we would ordinary say - is possessed by John-at- $t$. For reason of space, I shall not investigate how the identification can be achieved given Complex. Instead, I shall focus on the strength of Complex itself.

${ }^{26}$ By (Event-Nature), events are states of affairs.

${ }^{27}$ As in Section 3. The difference with that section is that, there, I took for granted that $x$-at- $t$ 's having a temperature of $30{ }^{\circ} \mathrm{C}$ is an event; here, I am making such a thesis plausible.
} 
$x$-at- $t$ can enter into before-after relations. In fact, it is a state of affairs one of whose constituents is $x$-at- $t$. Temporal parts can enter into before-after relations. This state of affairs inherits the before-after relations which $x$-a- $t$ enters into. As a conclusion, given plausible and natural assumptions concerning our causal and observability reports, it follows that $T$ is a universal that allows the exemplification of the universal $T$ by $x$-at- $t$ to satisfy all the requirements for being an event. But, then, it is plausible to conclude that there is an event $e$ identified with the exemplification of the universal $T$ by $x$-at- $t$. Hence, it is plausible to consider $T$ an eventive universal, contra Complex.

We considered a situation in which $x$-at- $t$ has the universals of having $a$ temperature of $30{ }^{\circ} \mathrm{C}$ and having a mass of $15 \mathrm{~kg}$. According to Complex, these universals are not eventive. Complex claims, $x$-at- $t$ has exactly a single eventive universal $P$ somehow built out from the previous two universals. Under plausible and natural assumptions concerning our causal and observability reports, we showed, contra Complex, that the "constituent" universals having a temperature of $30{ }^{\circ} \mathrm{C}$ and having a mass of $15 \mathrm{~kg}$ are eventive. But, then, since Complex clashes with these plausible assumptions, it is a rather costly strategy the identifier may adopt to resist the $A I D$ argument.

\subsubsection{The Simple Solution}

Simple develops The Single Eventive Universal Thesis differently than Complex. Consider a temporal part $x$-at- $t$ that has a temperature of $30{ }^{\circ} \mathrm{C}$ and a mass of $15 \mathrm{~kg}$. Simple says that $x$-at- $t$ does not have the distinct universals of having a temperature of $30{ }^{\circ} \mathrm{C}$ and having a mass of $15 \mathrm{~kg}$. According to Simple, $x$-at- $t$ has just a single simple eventive universal: the universal of having a temperature of $30{ }^{\circ} \mathrm{C}$ while having a mass of $15 \mathrm{~kg}$ while... ("TM" for short). This universal is simple or atomic: it is not built out of other universals. In particular, it is not built out of the universals of having a temperature of $30{ }^{\circ} \mathrm{C}$ and having a mass of $15 \mathrm{~kg}$. According to Simple, $x$ at- $t$ does not have other eventive universals besides $T M .^{28}$ Therefore, there is just one event $e$ in which $x$-at- $t$ participates - the event identified with the exemplification of the eventive universal $T M$ by $x$-at- $t$. But, then, the AID argument is blocked. ${ }^{29}$

Simple is a conjunction of three theses. First, The Single Eventive Universal Thesis: every temporal part $x$-at- $t$ of some object $x$ can have at most one eventive universal $P_{1^{-}}$ ing while $P_{2}$-ing while... Second, such an eventive universal $P_{1}$-ing while $P_{2}$-ing while... is a simple (hence the name of the solution) universal that is not built out of other universals $P_{1}, P_{2}, \ldots$ Third, the temporal part $x$-at- $t$, that has such an eventive universal $P_{1}$-ing while $P_{2}$-ing while..., does not have the universals $P_{1}, P_{2}, \ldots$ which intuitively seem to build it. ${ }^{30}$

\footnotetext{
28 This solution generalizes in the obvious way to more complex situations.

${ }^{29}$ Simple can be adopted by the identifiers provided that they assume a view similar to that mentioned in footnote 25. As for Complex, I shall not investigate how the identification can be achieved given Simple. Instead, I shall focus on the strength of Simple itself.

${ }^{30}$ If $x$-at- $t$ also had those universals, then considerations similar to those against Complex would apply. As a conclusion, such universals would plausibly be eventive. Hence, the AID argument would plausibly hold.
} 
Simple is a costly strategy. In particular, the explanation of similarities between objects provided by Simple is worse than that provided by the "standard" theories of universals. Consider a situation in which two temporal parts of two spheres, $S p_{1}$ and $S p_{2}$, are involved:

(5) $S p_{1}-$ at- $t$ has a temperature of $30^{\circ} \mathrm{C}$ and a mass of $15 \mathrm{~kg}$.

(6) $S p_{2}-a t-t$ has a temperature of $200^{\circ} \mathrm{C}$ and a mass of $15 \mathrm{~kg}$.

According to the "standard" theories of universals, $S p_{1}$-at- $t$ and $S p_{2}$-at- $t$ are partly similar because they share numerically the same eventive universal of having a mass of $15 \mathrm{~kg}$, and they are partly different because they have two different eventive universals of temperature. Simple cannot apply such an explanation of similarity in every situation in which it is applied by the "standard" theories of universals. For instance, according to Simple, $S p_{1}$-at- $t$ has the single simple eventive universal of having a temperature of $30^{\circ} \mathrm{C}$ while having a mass of $15 \mathrm{~kg}$ while... ("TM" for short); whereas $S p_{2}$-at- $t$ has the single simple eventive universal of having a temperature of $200{ }^{\circ} \mathrm{C}$ while having a mass of $15 \mathrm{~kg}$ while... (" $T^{*} M^{\prime}$ " for short). Since the temperature of $30{ }^{\circ} \mathrm{C}$ is different from the temperature $200{ }^{\circ} \mathrm{C}, T M$ is different from $T^{*} M$. But, then, $S p_{1}$-at- $t$ and $S p_{2}$-at- $t$ have completely different eventive universals. Hence, Simple cannot say that $S p_{1}$-at- $t$ and $S p_{2}$-at- $t$ have the same mass $15 \mathrm{~kg}$ because they share the same universal of having a mass of $15 \mathrm{~kg}$. One natural strategy for explaining the fact that $S p_{1}$-at- $t$ and $S p_{2}$-at- $t$ are partly similar is by saying that $T M$ and $T^{*} M$ are partly similar in a primitive way.

The explanation of similarity between objects given by the theories of universals has been considered one of the most forceful arguments for the existence of universals (Armstrong 1978; Peacock 2009). The fact that Simple cannot apply such an account of similarity to every situation in which it is intuitively required, the fact that the "standard" theories of universals can apply such an explanation of similarity to those situations in which it is intuitively required, and the fact that Simple seems forced to explain many similarities between objects in terms of brute facts between universals, together make the explanation provided by Simple less plausible than that provided by the "standard" theories of universals. In short, the explanation of similarity proposed by Simple is worse than that proposed by "standard" theories of universals. But, then, Simple is a costly strategy the identifier may adopt to resist the AID argument.

Summing up: I investigated whether The Single Eventive Universal Thesis can be adopted to resist the $A I D$ argument. Such a thesis can be developed in two different accounts: Complex and Simple. It turns out that both accounts are rather costly. However, this is not my main reason why the identifier should not adopt Complex or Simple to resist the AID argument. Such a reason will be postponed to section 4.3.2 where austere nominalism is taken into consideration.

\subsection{The Nominalist Solutions}

The AID argument bears on premise (III), according to which the thesis that events are exemplifications of eventive universals plus principles (Event-Nature), (Existence Condition), and (Identity Condition) all require some sort of commitment to eventive universals. However, the commitment to universals, such as having a temperature of $30{ }^{\circ} \mathrm{C}$ and having a mass of $15 \mathrm{~kg}$, is a metaphysically loaded thesis that can be very 
well resisted. Hence, suppose one adopts a nominalist stance concerning universals. ${ }^{31}$ It immediately follows that the thesis that events are exemplifications of eventive universals plus principles (Event-Nature), (Existence Condition), and (Identity Condition) are not adequate principles concerning the metaphysics of events. Moreover, it follows that the premise of the $A I D$ argument according to which a temporal part $x$-at- $t$ can have distinct eventive universals is false (and, so, this strategy takes care of option (ii) of section 4.2). Therefore, if one adopts the nominalist stance concerning universals, then the $A I D$ argument is blocked.

The nominalist position comes in two flavours (Rodriguez-Pereyra 2015; Loux and Crisp 2017): (a) the view according to which there are properties, but these are particular properties that cannot be shared in the way universals can. (b) The view according to which there are no properties - i.e. universals or particular properties - at all. Both strategies block the AID argument. However, as I shall argue, the supporter of the Identification Thesis can adopt only the view (b), according to which there are no properties - i.e. universals or particular properties - at all.

\subsubsection{The Eventive Trope Solutions}

The first nominalist strategy maintains that there are particular properties - traditionally called "tropes", "modes", or "moments" -, but no universals at all. ${ }^{32}$ The present view says that the particular red of my sweater ${ }^{33}$ is due to a red-trope. Such a red-trope is different from any other red-trope present in objects distinct from my sweater. Moreover, according to the present account, such a red-trope is an abstract entity ${ }^{34}$ - it can occur in the same spatio-temporal region in conjunction with many other distinct tropes, such as the mass-trope of $300 \mathrm{~g}$ of my sweater. ${ }^{35}$ Among the philosophers who have taken up this view, one could mention Williams (1953), Mulligan et al. (1984), Campbell (1990), Maurin (2002), and Heil (2003).

Within such a position, events are identified with certain kinds of tropes or bundles of tropes (Bennett 1988; MacDonald and Macdonald 2006) - call them "eventive tropes". ${ }^{36}$ Examples includes tropes like the particular temperature of $30{ }^{\circ} \mathrm{C}$ of that sphere-at- $t$, or its particular mass of $15 \mathrm{~kg}$. I shall argue that the supporters of the Identification Thesis cannot adopt the view of events as eventive tropes to block the $A I D$ argument. To this end, I shall distinguish two main conceptions of the notion of trope at stake.

\footnotetext{
${ }^{31}$ One might react to such a strategy by saying that she is still committed to universals like having a temperature of $30^{\circ} \mathrm{C}$ and having a mass of $15 \mathrm{~kg}$, but she does not take them to be eventive. This move is not really plausible, as section 4.2.1 has shown.

${ }^{32}$ As it may be pointed out, some trope-theorists may specify their position by saying that there are no primitive universals. According to such a view, universals are made up from or grounded in tropes. I leave such a complication aside.

${ }^{33}$ When I speak about my sweater or any other object, I am speaking loosely. What I shall say is my sweater $t$ temporal part.

${ }^{34}$ For such a notion of being abstract see, e.g., (Williams 1953; Bennett 1988; Maurin 2018).

${ }^{35}$ Furthermore, tropes are primarily qualitative (Maurin 2002, pp. 21-24; Loux and Crisp 2017, p. 75): this fact means that tropes have their characters - i.e. their qualitative natures - in a primitive way.

${ }^{36}$ Since events - that perdure - are eventive tropes and since tropes are tropes of objects' temporal parts, I shall make the assumption that tropes perdure.
} 
The first conception maintains that tropes are individual accidents, or particularized and non-substantial ways objects are (Mulligan et al. 1984; Heil 2003). According to this conception, tropes characterize the objects' temporal parts that have them. Moreover, tropes are non-identical to, and depend on, the temporal parts that have them. Since events are eventive tropes, it follows that events are not identical to objects' temporal parts. Hence, this conception of tropes cannot be compatible with the Identification Thesis.

According to the second conception, tropes are the basic constituents of Reality. They are conceived of as substances - not different in kind from ordinary objects -, and they are what ordinary objects are made up of(Williams 1953; Campbell 1990; Maurin 2002). This conception of tropes, called "bundle theory of tropes", commits to an operation of constitution $^{37}$ that takes as arguments certain maximal and consistent collections of tropes and gives as values temporal parts of ordinary objects. Let us call "constituents" the tropes that figure as arguments of such an operation.

Given the present framework, the task of providing an adequate definition of the notion of participation between an event and an object's temporal part is a tricky matter. ${ }^{38}$ An adequate definition of participation must include a criterion that allows us to select among the tropes that help to constitute a temporal part $x$-at- $t$ those that are 'maximal'. With this expression I mean the following. Suppose that $x$-at- $t$ has a mass of $15 \mathrm{~kg}$. Then, the criterion must be able to select just its constituent trope of having a mass of $15 \mathrm{~kg}$ - but, not a trope of having a mass of $10 \mathrm{~g}$ that helps to constitute a proper part of $x$-at- $t$. I simply assume that such a principled criterion to select the 'maximal' tropes is available for the friends of the bundle theory of tropes. Then, we can define the notion of participation as follow:

(Trope-Participation) A temporal part $x$-at- $t$ of an object $x$ is the participant of an event $e$ if and only if such an event $e$ is a maximal eventive trope that helps to constitute $x$-at- $t$.

Given (Trope-Participation), we can show that the bundle theory of tropes implies the rejection of the Identification Thesis. ${ }^{39}$ According to any bundle theory of tropes, at least some ordinary objects' temporal parts are constituted by two or more distinct maximal tropes. Consider an ordinary object's temporal part $x$-at- $t$ that is constituted by a maximal eventive trope of having a mass of $15 \mathrm{~kg}$ and by a distinct maximal trope $z$ ( $z$ may be eventive, but it needs not to be). Then, $x$-at- $t$ is different from the trope of having a mass of

\footnotetext{
${ }^{37}$ Such an operation is accounted differently within different theories of tropes (Maurin 2002; Paul 2002).

${ }^{38}$ The problem is the following. We want to say that if a temporal part $x$-at- $t$ of an object $x$ is the participant of an event $e$, then such an event $e$ is an eventive trope that helps to constitute $x$-at- $t$. For instance, if $x$-at- $t$ is the participant of its state of having a mass of $15 \mathrm{~kg}$, such a state is an eventive trope - the trope of having a mass of $15 \mathrm{~kg}$ - that helps to constitute $x$-at- $t$. However, not every eventive trope $e$ that helps to constitute $x$-at- $t$ is an event that has $x$-at- $t$ as its intended participant (for the notion of minimal or intended participant see footnote $20)$. For instance, suppose that $x$-at- $t$ has a mass of $15 \mathrm{~kg}$. There may be an eventive trope of having a mass of $10 \mathrm{~g}$ that helps to constitute $x$-at- $t$. But, $x$-at- $t$ is not the intended participant of state of having a mass of $10 \mathrm{~g}$. If any, the intended participant of such a state is one of $x$-at- $t$ 's proper parts - not $x$-at- $t$.

${ }^{39}$ For the sake of argument, assume that at least some of the tropes that help to constitute any temporal part of any object is eventive, i.e. an event. This assumption is required. In fact, without it, it may be possible that there is a temporal part of some object that does not participate in any event. But, then, the assumption presupposed to the Identification Thesis - according to which every temporal part participates in some event would be false.
} 
$15 \mathrm{~kg}$. Since the trope of having a mass of $15 \mathrm{~kg}$ is a maximal eventive trope that helps to constitute $x$-at- $t$, (Trope-Participation) implies that $x$-at- $t$ is the participant of its state of having a mass of $15 \mathrm{~kg}$. But, then, $x$-at- $t$ is the participant of its state of having a mass of $15 \mathrm{~kg}$ and it is different from it, contra the Identification Thesis. Hence, the bundle theory of tropes is not compatible with the Identification Thesis.

The conclusion of the present section is that none of the two nominalist conceptions of tropes is compatible with the Identification Thesis. In the next section, I show that accepting austere nominalism is the best strategy a supporter of the Identification Thesis can take in order to resist the AID argument.

\subsubsection{The Austere Nominalist Solution}

Austere nominalism is one of the ways to account for the thesis that there are no properties - i.e. universals or particular properties - at all. According to this framework, objects have characteristics such as having a mass of $15 \mathrm{~kg}$, having a temperature of $30{ }^{\circ} \mathrm{C}$, or having a unit negative charge. Characteristics like these constitute, at least partly, the so-called "character" or "qualitative nature" of an object. However, austere nominalism maintains that the fact that objects have such characteristics is metaphysically primitive: for instance, a sphere has a mass of $15 \mathrm{~kg}$ because it has a mass of $15 \mathrm{~kg}$. There is no further metaphysical explanation of this fact - in particular, there is no further explanation that commits to properties of any kind. Moreover, according to its supporters, austere nominalism provides an adequate explanation of similarity between objects: the fact that $a$ and $b$ have both a mass of $15 \mathrm{~kg}$ is grounded in the facts that $a$ has a mass of $15 \mathrm{~kg}$ and $b$ has a mass of $15 \mathrm{~kg}$ (Devitt 1980; Imaguire 2014). ${ }^{40}$

Accepting austere nominalism is the best strategy a supporter of the Identification Thesis can take in order to resist the AID argument. My claim is based on three reasons. As to the first reason, the two views support each other. On the one hand, austere nominalism allows the Identification Thesis to block the AID argument. On the other hand, the package constituted by the Identification Thesis and austere nominalism defuses a major problem for austere nominalism. Indeed, this package provides austere nominalism with an account of events as spatio-temporal particulars which is not based on properties - whose existence austere nominalism denies.

As to the second reason, austere nominalism shares the same motivations that support the Identification Thesis. First, one of the main reasons for both the Identification Thesis and austere nominalism has been the appeal to ontological parsimony. For instance, austere nominalists such as Devitt (1980) and Imaguire (2014) reject universals because they constitute - in their view - unnecessary commitments. Second, supporters of both positions base their views on the quest for clear-cut identity criteria for existing things. On the one hand, the supporter of the Identification Thesis argues, if events were distinct from temporal parts of objects, we could not provide any adequate criterion of identity for events. On the contrary, if we adopt the Identification Thesis, we have an apparently non-problematic criterion of identity for events - i.e., that for perduring objects (Quine 1985). On the other

\footnotetext{
${ }^{40}$ Austere nominalism seems compatible with the Identification Thesis. To make this plausible, consider, for instance, the event-nominal " $x$-at- $t$ 's having of $P$ " and its associated true sentence " $x$-at- $t$ has $P$ ". According to the Identification Thesis, the referent of such a nominal is $x$-at- $t$. According to austere nominalism, the truthmaker of the sentence is also $x$-at- $t$.
} 
hand, austere nominalists argue, realists on universals cannot provide a non-circular and non-regressive criterion of identity for universals. So, it is better to do without them (Quine 1975). ${ }^{41}$ Hence, these two positions fit perfectly together.

As to the third reason, Complex and Simple - that also block the AID argument - do not match well with the Identification Thesis. The reason is that they do not share the same motivations that support the Identification Thesis. Indeed, insofar as such positions admit the existence of universals, they are not driven by the quest for ontological parsimony and the quest for clear-cut identity criteria for existing things. But, without such principles, the motivations for the Identification Thesis are lost. In conclusion, these reasons taken together ground the claim that the supporter of the Identification Thesis should resist the AID argument by adopting austere nominalism.

As a matter of fact, the same reasons suggest a stronger conclusion. In particular, the first two reasons show that also the Identification Thesis is a perfect partner for austere nominalism. Hence, all these reasons taken together suggest the conclusion that austere nominalism and the Identification Thesis fit so nicely together that they should be considered a unique package. In turn, such a result means that these positions should be re-evaluated as a whole and not separately. ${ }^{42}$

A final objection must be considered. The objection says that austere nominalism is not more plausible than Complex and Simple are. Indeed, the objection goes, austere nominalism suffers from well-known difficulties - such as the problem of abstract reference - that undermine its plausibility. ${ }^{43}$ Hence, the objection concludes, since austere nominalism and the Identification Thesis constitute a unique package, the Identification Thesis should be rejected as a consequence of the refutation of austere nominalism. I reply that such an objection misunderstands the aims of the present paper. On the one hand, this article does not aim to establish, once and for all, the plausibility of austere nominalism. On the other hand, such an objection is based exactly on one of the results of this paper - i.e., the thesis that austere nominalism and the Identification Thesis should be considered a unique package. Hence, if austere nominalism is implausible, then the Identification Thesis is implausible as well.

Summing up: accepting austere nominalism is the best strategy a supporter of the Identification Thesis can take in order to resist the AID argument. Moreover, these views fit so nicely together that they should be considered a unique package. However, austere nominalism is beset by significant costs. Hence, if such a view has to be rejected, my conclusion is that the Identification Thesis must be rejected as well.

\footnotetext{
${ }^{41}$ In particular, the quest for adequate criteria of identity connects the two positions in the following way. If events were distinct from temporal parts of objects, one potential criterion of identity for events would be in terms of universals - as, e.g., in Kim's view presented in Section 3. However, an identifier like Quine would reply that the adequacy of this criterion would, in turn, depend on an adequate criterion of identity for universals. Though, no adequate criterion of the latter kind can be formulated.

${ }^{42}$ It is remarkable to note that such a package amounts to Quine's overall view. Indeed, Quine has been one of the most well-known advocates of both austere nominalism and the Identification Thesis. However, as far as I know, he never explicitly recognized the tight connection between these two views. So, he never explicitly suggested that these positions should be evaluated together.

${ }^{43}$ The problem of abstract reference says that there are true sentences like:

(*) Courage is a moral virtue, which seem to contain abstract singular terms, such as "Courage", naming universals. Austere nominalism must provide a paraphrase of sentences like $(*)$ that does not commit to universals, but only to concrete objects. The problem for austere nominalism is that none of its paraphrase strategies seem completely adequate (Loux and Crisp 2017, pp. 54-57). For a detailed account of the main objections against austere nominalism see, e.g., (Peacock 2009) and (Loux and Crisp 2017, pp. 50-60).
} 


\section{Conclusion}

On the assumption of perdurance theory for both events and objects, some philosophers argued for the Identification Thesis. According to its supporters, such a view is motivated by ontological parsimony and the quest for clear-cut identity criteria for existing things. However, one of the most well-accepted theories of events, the theory of events as property-exemplifications, allows us to formulate the AID argument against the identification. The paper investigates several attempts the identifier may adopt to block the $A I D$ argument. This investigation has an unexpected result, namely, that accepting austere nominalism is the best strategy a supporter of the Identification Thesis can take in order to resist the AID argument. Moreover, I also suggested that these views should be considered as a unique package.

These results are relevant for a number of reasons. For one thing, such a package provides a fruitful metaphysical framework, constituted by the Identification Thesis and austere nominalism, that should be evaluated as a whole. For another, if austere nominalism turned out not to be plausible, then the Identification Thesis should be rejected as well.

Acknowledgements I would like to thank Claudio Calosi, Pierdaniele Giaretta, Daniel Giberman, Matteo Morganti, Julien Murzi, Donnchadh O'Conaill, Martin Pickup, Thomas Sattig, Maria Scarpati, Tuomas Tahko, Achille C. Varzi for invaluable suggestions and comments. Also, I want to thank the audiences at the Ontoformat Seminars (Milan), The Future of Swiss Philosophy Workshop (Ligerz), The Nordic Network in Metaphysics Conference (Tampere), and the 13th International Symposium of Cognition, Logic and Communication (Riga) for their questions and comments.

Funding Information Open Access funding provided by Projekt DEAL. This work was supported by the DAAD Scholarship under grant number 91645817; and the Ernst Mach Grant - worldwide under grant number ICM-2018-09910.

\section{Compliance with Ethical Standards}

Conflict of Interest The author reports no conflict of interest.

Open Access This article is licensed under a Creative Commons Attribution 4.0 International License, which permits use, sharing, adaptation, distribution and reproduction in any medium or format, as long as you give appropriate credit to the original author(s) and the source, provide a link to the Creative Commons licence, and indicate if changes were made. The images or other third party material in this article are included in the article's Creative Commons licence, unless indicated otherwise in a credit line to the material. If material is not included in the article's Creative Commons licence and your intended use is not permitted by statutory regulation or exceeds the permitted use, you will need to obtain permission directly from the copyright holder. To view a copy of this licence, visit http://creativecommons.org/licenses/by/4.0/.

\section{References}

Armstrong, D. M. (1978). A theory of universals. Universals and scientific realism Voll II. Cambridge: Cambridge University Press.

Armstrong, D. M. (1997). A world of states of affairs. Cambridge: Cambridge University Press.

Bennett, J. (1988). Events and their names. Oxford: Oxford University Press.

Bennett, J. (1996). What events are. In R. Casati \& A. C. Varzi (Eds.), Events (pp. 137-151). Aldershot: Dartmouth. And in: R.M. Gale (Ed.) (2002). The Blackwell Guide to Metaphysics (pp. 43-65). Hoboken (NJ): Wiley-Blackwell Publishers. 
Brand, M. (1977). Identity conditions for events. American Philosophical Quarterly, 14(4), 329-337.

Campbell, K. (1990). Abstract Particulars. Oxford: Basil Blackwell.

Casati, R., \& Varzi, A.C. (2014). Events, The Stanford Encyclopedia of Philosophy (winter 2015 edition), Edward N. Zalta (Ed.). https://plato.stanford.edu/archives/win2015/entries/events/.

Davidson, D. (1967a). The logical form of action sentences. In N. Rescher (Ed.), The logic of decision and action (pp. 81-95). Pittsburgh: University of Pittsburgh Press.

Davidson, D. (1967b). Causal relations. The Journal of Philosophy, 64, 691-703.

Devitt, M. (1980). “Ostrich nominalism” or "mirage realism”? Pacific Philosophical Quarterly, 61, 433-439.

Fine, K. (1982). First-order modal theories III-Facts. Synthese, 53(1), 43-122.

Goldman, A. (1970). A theory of human action. Upper Saddle River: Prentice-Hall.

Goodman, N. (1951). The structure of appearance. Cambridge: Harvard University Press.

Hacker, P. M. S. (1982). Events and objects in space and time. Mind, 91(361), 1-19.

Heil, J. (2003). From an ontological point of view. Oxford: Oxford University Press.

Imaguire, G. (2014). In Defence of Quine's ostrich nominalism. Grazer Philosophische Studien, 89, 185-203.

Kim, J. (1973). Causation, Nomic Subsumption, and the concept of events. The Journal of Philosophy, 70(8), $217-236$.

Kim, J. (1976). Events as property exemplifications. In M. Brand \& D. Walton (Eds.), Action Theory (pp. 159-177). Dordrecht/Boston: Reidel. And in J. Kim (Ed.) 1993(1995), Supervenience and Mind (pp. 3352). Cambridge/New York: Cambridge University Press.

Lewis, D. K. (1986). On the plurality of worlds. Oxford: Basil Blackwell.

Lombard, L. B. (1979). Events. Canadian Journal of Philosophy, 9(3), 425-460.

Lombard, L. B. (1998). Ontologies of events. In C. Macdonald \& S. Laurence (Eds.), Contemporary Reading in the Foundation of Metaphysics (pp. 277-294). Oxford: Blackwell.

Loux, M. J., \& Crisp, T. M. (2017). Metaphysics. A contemporary introduction (Fourth ed.). New York: Routledge.

Lowe, J. E. (1998). The possibility of metaphysics. Oxford: Oxford University Press.

Lowe, J. E. (2006). The four-category ontology. Oxford: Oxford University Press.

Macdonald, C., \& Macdonald, G. (2006). The metaphysics of mental causation. The Journal of Philosophy, 103(11), 539-576.

Maurin, A.-S. (2002). If tropes. Dordrecht: Kluwer Academic Publishers.

Maurin, A-S. (2018). Tropes, The Stanford Encyclopedia of Philosophy (summer 2018 edition), Edward N. Zalta (Ed.). http://plato.stanford.edu/archives/sum2018/entries/tropes/.

McDonnell, N. (2016). Events and their counterparts. Philosophical Studies, 173, 1291-1308.

Menzies, P. (2014). Counterfactual theories of causation, in: E. N. Zalta (Ed.), The Stanford Encyclopedia of Philosophy (spring 2014 edition). https://plato.stanford.edu/archives/spr2014/entries/causationcounterfactual/.

Moreland, J. P. (1996). Issues and options in exemplification. American Philosophical Quarterly, 33(2), 133147.

Moreland, J. P. (1998). Theories of individuation: A reconsideration of bare particulars. Pacific Philosophical Quarterly, 79(3), 251-263.

Mulligan, K., Simons, P. M., \& Smith, B. (1984). Truth-makers. Philosophy and Phenomenological Research, 44, 287-321.

Paul, L. A. (2002). Logical parts. Nô̂s, 36(4), 578-596.

Peacock, H. (2009). What's wrong with ostrich nominalism? Philosophical Perspective, 38(2), 183-217.

Pianesi, F., \& Varzi, A. C. (2000). Events and event talk: An introduction. In J. Higginbotham, F. Pianesi, \& A. C. Varzi (Eds.), Speaking of events (pp. 3-47). New York/Oxford: Oxford University Press.

Quine, W. V. O. (1950). Identity, Ostention and Hyposthasis. The Journal of Philosophy, 47, 621-633.

Quine, W. V. O. (1960). Word and object. Cambridge, MA: MIT Press.

Quine, W. V. O. (1975). On the individuation of attributes. In A. R. Anderson, R. B. Marcus, \& R. M. Martin (Eds.), The logical Enterprise: Essays for Frederic B. Fitch (pp. 3-13). New Haven (CT): Yale University Press.

Quine, W. V.O. (1976). Whither physical objects? In R. S. Cohen, P. K. Feyerabed, \& M. W. Wartofsky (Eds.), Essays in Memory of Imre Lakatos (pp. 497-504). Dordrecht|Boston: Reidel.

Quine, W. V. O. (1985). Events and reification. In E. Lepore \& B. McLaughlin (Eds.), Actions and events. Perspectives on the philosophy of Donal Davidson (pp. 162-171). Oxford: Blackwell.

Quinton, A. (1979). Objects and events. Mind, 88(350), 197-214.

Reichenbach, H. (1956). The direction of time. Berkley/Los Angeles/London: University of California Press. 
Rodriguez-Pereyra, G. (2015). Nominalism in metaphysics, The Stanford Encyclopedia of Philosophy (winter 2016 edition), Edward N. Zalta (Ed.). https://plato.stanford.edu/archives/win2016/entries/nominalismmetaphysics/.

Simons, P. (1987). Parts: A study in ontology. Oxford: Oxford University Press.

Stout, R. (2016). The category of Occurrent continuants. Mind, 125(497), 41-62.

Strawson, P. F. (1959). Individuals: An essay in descriptive metaphysics. London: Methuen.

Varzi, A. C. (2002). Events, truth, and indeterminacy. The Dialogue, 2, 241-264.

Williams, D. C. (1953). On the elements of being. Review of Metaphysics, 7(1), 3-18.

Publisher's Note Springer Nature remains neutral with regard to jurisdictional claims in published maps and institutional affiliations. 